This is the postprint version of the following article: Bodelón G, Montes-Garcia V, Fernández-López C, Pastoriza-Santos I, Pérez-Juste J, Liz-Marzán LM. Au@pNIPAM SERRS Tags for Multiplex Immunophenotyping Cellular Receptors and Imaging Tumor Cells. Small 2015;11(33):4149-4157, which has been published in final form at 10.1002/smll.201500269. This article may be used for non-commercial purposes in accordance with Wiley Terms and Conditions for Self-Archiving. 


\title{
Au@pNIPAM SERRS tags for multiplex immunophenotyping cellular receptors and imaging tumor cells
}

\author{
Gustavo Bodelón, Verónica Montes-García, Cristina Fernández-López, Isabel \\ Pastoriza-Santos, Jorge Pérez-Juste * and Luis M. Liz-Marzán ${ }^{*}$
}

\author{
Dr. G. Bodelón V. Montes-García, C. Fernández-López, Dr. I. Pastoriza-Santos, Dr. J. \\ Pérez-Juste, Prof. L. M. Liz-Marzán \\ Departmento de Química Física, Universidade de Vigo \\ 36310 Vigo (Spain) \\ E-mail: juste@uvigo.es, llizmarzan@cicbiomagune.es \\ Prof. L. M. Liz-Marzán \\ Bionanoplasmonics Laboratory, CIC biomaGUNE \\ Paseo de Miramón 182, 20009 Donostia - San Sebastián (Spain) \\ Prof. L. M. Liz-Marzán \\ Ikerbasque, Basque Foundation for Science \\ 48011 Bilbao (Spain)
}

Keywords: bioimaging, SERRS, gold nanoparticles, microgels, multiplex 


\begin{abstract}
Detection technologies employing optically encoded particles have gained much interest toward clinical diagnostics and drug discovery, but the portfolio of available systems is still limited. We report the fabrication and characterization of highly stable surface enhanced resonance Raman scattering (SERRS)-encoded colloids, for the identification and imaging of proteins expressed in cells. These plasmonic nanostructures are made of gold octahedra coated with poly(isopropylacrylamide) (Au@pNIPAM) microgels and can be readily encoded with Raman active dyes while retaining high colloidal stability in biofluids. A layer-by-layer polyelectrolyte coating was used to seal the outer surface of the encoded particles and to provide a reactive surface for covalent conjugation with antibodies. The targeted multiplexing capabilities of the SERRS tags was demonstrated by the simultaneous detection and imaging of three tumor-associated surface biomarkers EGFR, EpCAM and CD44 by Raman spectroscopy. The plasmonic microgels were able to discriminate tumor A431 (EGFR+/EpCAM+/CD44+) and non-tumor 3T3 2.2 (EGFR-/EpCAM-/CD44+) cells while co-cultured in vitro.
\end{abstract}




\section{Introduction}

The identification of multiple protein biomarkers expressed on cell membranes or tissues is of high relevance for accurate diagnosis, disease staging, prognosis and guiding the design of more efficient therapeutic interventions. ${ }^{[1-4]}$ Hence, sensitive platforms for simultaneous detection of multiple analytes from a single specimen have emerged as highly demanded tools in biomedicine, drug discovery or cell imaging. ${ }^{[5,6]}$ Most of the multiplexing technologies, such as real time (RT)-PCR, DNA microarray, enzyme-linked immunoassay, confocal laser scanning microscopy (CLSM) or laser scanning flow cytometry (LSFC), involve the use of fluorescent probes such as small organic dyes or quantum dots. ${ }^{[4,7-12]}$ Among them, CLSM and LSFC have become indispensable cell-imaging tools and thus are broadly used for the interrogation of surface receptors present in cells employing fluorescently labeled antibodies (i.e. immunophenotyping). ${ }^{[13]}$ However, the simultaneous detection of different fluorophores is usually hindered by the broad emission spectra $(>30 \mathrm{~nm})$ and the requirement of multiple excitation wavelengths. ${ }^{[14-17]}$ Therefore, the development of alternative optical imaging probes and detection methods is still required.

Surface enhanced Raman scattering (SERS) is a powerful vibrational spectroscopy technique that provides highly sensitive structural detection of analytes in very low concentrations, through the enhancement (up to $10^{14}$ ) of the characteristic ineslastic Raman scattering of the analyte molecules when they are close to or adsorbed onto nanostructured metal surfaces, such as gold or silver, sustaining localized surface plasmon resonances. ${ }^{[18]}$ Raman spectra can be seen as unique chemical fingerprints since each molecule has a different set of vibrational levels. ${ }^{[19-21]}$ Besides, as opposed to the wide spectra of fluorescence probes, SERS produces much narrower spectral peaks (1-2 nm vs. $50 \mathrm{~nm}$ for fluorescence bands), thereby leading to minimal spectral 
overlap. ${ }^{[14]}$ Therefore, SERS is inherently suitable for multiplex detection with almost unlimited multiplexing capability (broad reporter library). In addition, its high sensitivity that rivals that of fluorescence, the possibility of using a single excitation source, negligible photobleaching and low background, as well as low toxicity as compared to quantum dots, are additional advantages that have supported the translation of SERS into in vitro and in vivo biosensing. ${ }^{[19-23]}$ A further improvement in the sensitivity of Raman scattering spectroscopy arises from the resonance enhancement (surface enhanced resonance Raman scattering, SERRS) effect that takes place when the absorption maximum of the target molecule is close to or coincident with the Raman excitation laser wavelength. Thus, both enhancements, from the plasmon resonance and target molecular resonance contribute to obtaining even greater enhancement factors. ${ }^{\text {[24] }}$

SERS-encoded particles (or SERS tags) are an appealing new class of labeling contrast agents that have been developed for multiplex diagnostic assays and optical imaging. ${ }^{[14,25]}$ They comprise four main components: i) a metallic core that acts as SERS enhancer, ii) a Raman-active reporter molecule adsorbed onto the metallic surface to provide a distinct spectral signature, iii) a protective shell for stabilization of the SERS tags while providing a suitable surface for biofunctionalization and, iv) a targeting entity (e.g. antibody). ${ }^{[14,25]}$ The fabrication of these composite materials is a multistep process in which the plasmonic core serves as the anchoring-point for the attachment of Raman reporter molecules and coating with diverse types of materials including polyethylene glycol $(\mathrm{PEG}),{ }^{[26,}{ }^{27]}$ silica, ${ }^{[28-30]}$ proteins $^{[31]}$ and amphiphilic diblock copolymers ${ }^{[32]}$ or liposomes. ${ }^{[33]}$

Cell malignancies such as cancer are often characterized by specific bioreceptors present in their plasma membranes and the recognition of their expression pattern represents a crucial step in the diagnostic process. To date, a variety of SERS or SERRS 
tags have been reported for the detection and bioimaging applications of proteins expressed in cells. ${ }^{[27,34-38]}$ For example, Pallaoro et al. ${ }^{[37]}$ reported polymer-encapsulated Ag dimers codified with Methylene Blue or Thionin as Raman reporters and functionalized with either a peptide targeting the tumor-associated neuropilin-1 receptor or with a general cell penetrating peptide. This duplex SERRS tags could discriminate between noncancerous and cancerous prostate cells grown in vitro. Yuan et al. reported bovine serum albumin (BSA)-protected $\mathrm{Au}$ nanostars as SERRS probes for near infrared multiplexing of in vitro solutions and ex vivo tissue samples. ${ }^{[38]}$ However, only a few studies have demonstrated active targeting of more than two different receptors. $^{[27,34-36]}$

Hence, the development of sensitive plasmonic substrates allowing the simultaneous detection of multiple protein receptors has a great potential for cell identification and diagnostic procedures. In this context, we have synthesized a new class of SERRS-tags based on poly(N-isopropylacrylamide) (pNIPAM) encapsulated gold nanoparticles for the multiplex detection of tumor associated protein biomarkers. pNIPAM is a non-toxic ${ }^{[39,40]}$ and thermoresponsive polymer that has been applied as a scaffold for biological testing, tissue engineering, ${ }^{[41,42]}$ sensing or drug delivery applications, as well as in catalysis and photonics. ${ }^{[43-45]}$ Several examples have been reported on the encapsulation of metal nanoparticles within pNIPAM microgels for the fabrication of multifunctional hybrid platforms toward selective drug delivery, ${ }^{[46]}$ sensing, ${ }^{[47-50]}$ catalysts $^{[51,52]}$ or photothermal therapy, ${ }^{[53]}$ among others. The porous nature of pNIPAM microgels allowed us to fabricate a SERRS tag consisting of a gold octahedral nanoparticle codified with resonant Raman reporters and enclosed in a pNIPAM shell. A layer-by-layer outer polyelectrolyte coating was used to seal the porous encoded particles while facilitating covalent conjugation with antibodies that are 
specific against three different tumor biomarkers: epidermal growth factor receptor (EGFR), epithelial cell adhesion molecule (EpCAM) and homing cell adhesion molecule (CD44). These antibody-functionalized plasmonic microgels were tested for simultaneous multiplex detection of the three types of surface proteins by SERRS, thereby analyzing the possibility of discriminating between tumor A431 cells that express EGFR, EpCAM and CD44, and non-tumor 3T3 2.2 cells expressing CD44 only.
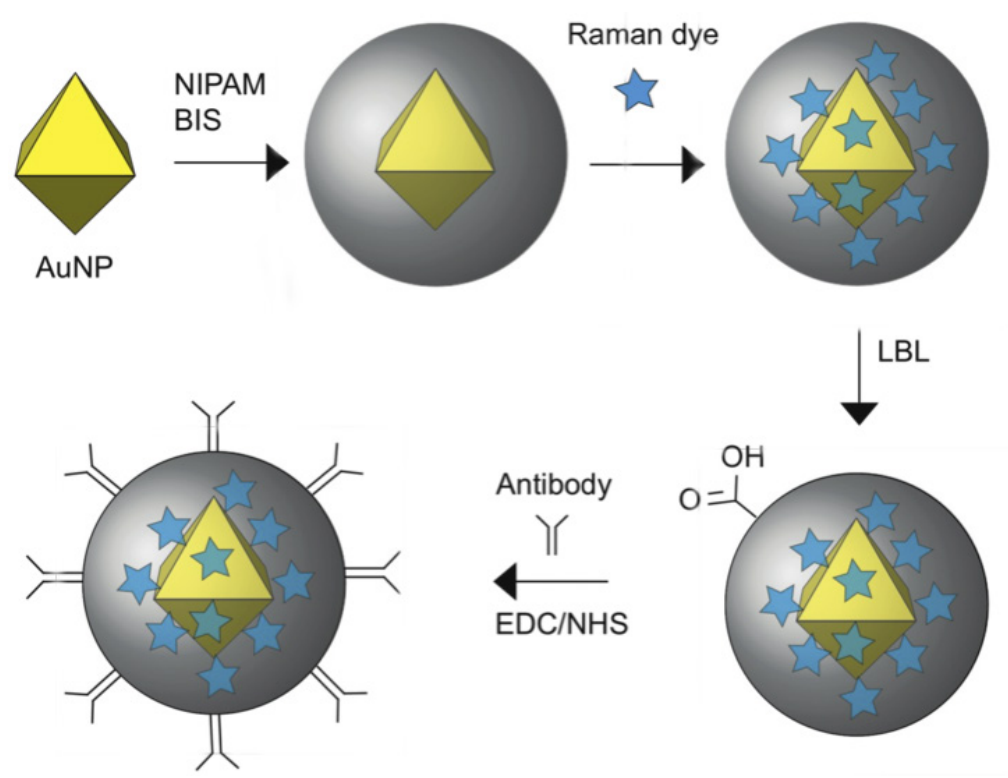

Scheme 1. Schematic representation of the preparation of Au@pNIPAM SERRSencoded tags.

\section{Results and discussion}

The synthesis of the SERRS tags, schematically depicted in Scheme 1, comprised four main steps: i) synthesis and pNIPAM encapsulation of relatively large (ca. $90 \mathrm{~nm}$ ) octahedral gold nanoparticles, ii) encoding of the hybrid particles with various Raman reporters, ii) surface functionalization with carboxylic acids through layer by layer polyelectrolyte assembly, and iv) bioconjugation witht selected antibodies through carbodiime chemistry. 
Octahedral $\mathrm{Au}$ nanoparticles $(87.1 \pm 4.3 \mathrm{~nm}$ side length, Figure S1) were synthesized through controlled seeded growth of single crystalline gold nanorods using butenoic acid as mild reducing agent, in the presence of the surfactant benzyldimethylhexadecylammonium chloride (BDAC). ${ }^{[50]}$ Interestingly, butenoic acid not only acted as a mild reducing agent but also provided the particles with vinyl functionality, thereby allowing direct pNIPAM polymerization on the particle surface via a grafting-through route, avoiding additional surface functionalization steps. ${ }^{[47]}$ The polymerization was carried out in water via a precipitation polymerization mechanism in the presence of a crosslinker, N,N'-methylenebisacrylamide (BIS) (see experimental section for details), resulting in highly monodisperse Au@pNIPAM core-shell structures (Figure 1A). Subsequently, encoding with Raman reporters was carried out by simply adding Raman active dyes (Astra Blue (AB), Nile Blue (NB) or Malachite Green Isothiocyanate (MGI)) to a colloidal dispersion of $\mathrm{Au} @$ pNIPAM microgels in water. After stirring the colloids overnight, to reach equilibrium, the surface functionalization with carboxylic acids was performed through layer by layer polyelectrolyte assembly (see experimental part for details). Thus, poly(acrilic acid) (PAA) and poly(allylamine hydrochloride) (PAH) were used as negatively and positively charged polyelectrolytes, respectively. Such surface modification prevented dye leaching, while providing carboxylic acid functional groups for the bioconjugation step. Excess dye molecules were removed by successive centrifugation and redispersion cycles performed during the polyelectrolyte assembly. The incorporation the dyes in the Au@pNIPAM microgels did not significantly affect their optical response, as demonstrated by UV-vis-NIR spectroscopy (Figure 1B). The slight differences observed in the absorbance bands (both in width and maximum wavelength), with respect to non 
encoded Au@pNIPAM microgels, were attributed to absorption by the dyes (see Figure 1C) at the LSPR spectral region.
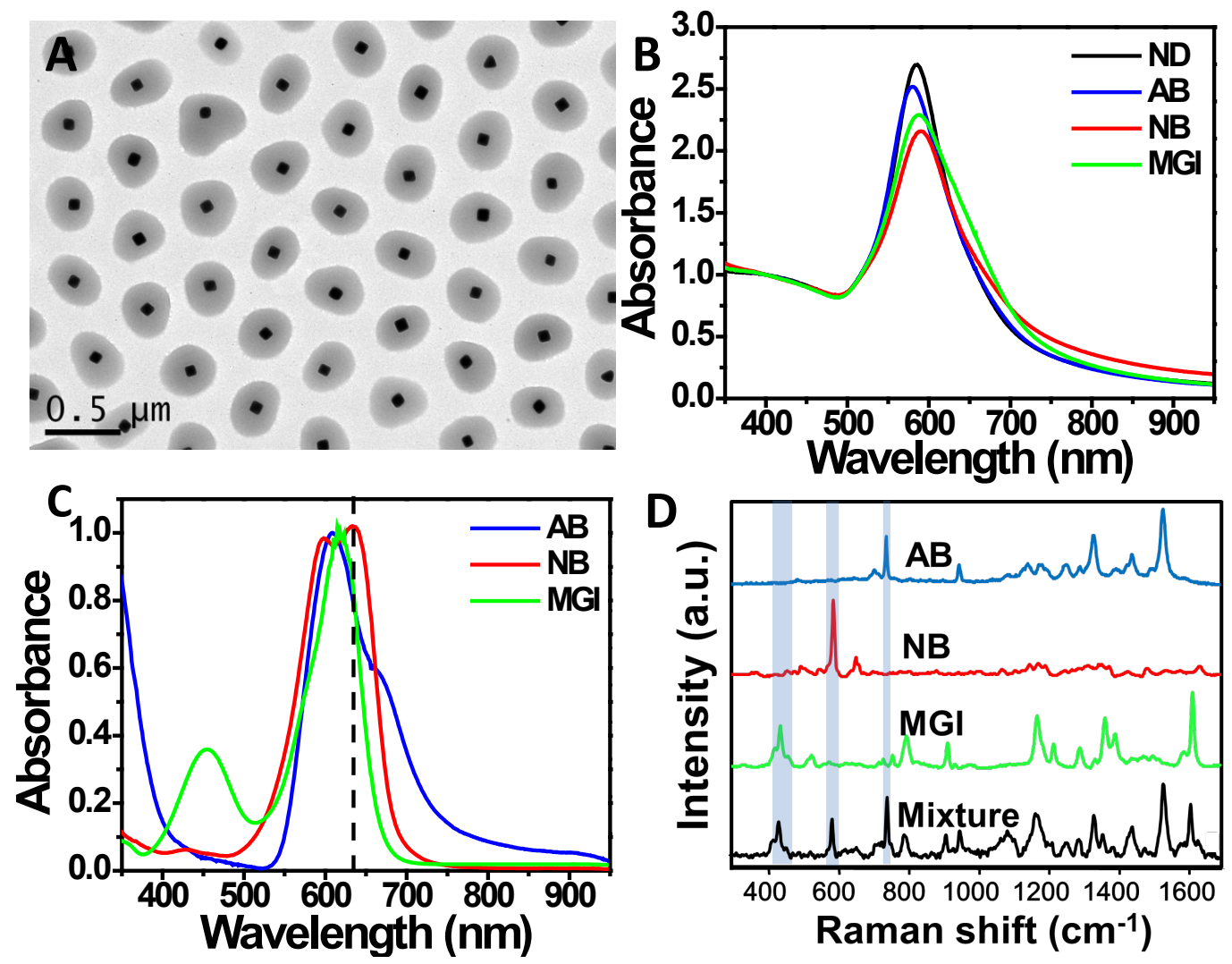

Figure 1. (A) Representative TEM image of Au@pNIPAM microgels. (B) UV-vis-NIR spectra of non-doped Au@pNIPAM microgels (ND, black); and doped with Astra Blue (AB, blue); Nile Blue (NB, red) and Malachite Green Isothiocyanate (MGI, green). (C) UV-vis-NIR spectra of AB in ethanol (blue); NB in ethanol (red) and MGI in methanol (green). (D) SERRS spectra of Au@pNIPAM microgels encoded with AB (blue); NB (red), MGI (green) and a mixture of the three. The excitation laser line was $633 \mathrm{~nm}$ in all cases.

The SERRS properties of the encoded particles were studied at $633 \mathrm{~nm}$ laser excitation as it matches the absorption maxima of the three selected dyes (Figure 1C). As shown in Figure 1D, each Au@pNIPAM SERRS tag displayed unique spectroscopic signatures (see vibrational assignments in Table S1) and more importantly, they 
showed distinguishable characteristic vibrational bands at $420 \mathrm{~cm}^{-1}$ (MGI), $592 \mathrm{~cm}^{-1}$ (NB) and $748 \mathrm{~cm}^{-1}(\mathrm{AB})$. Hence, the three probes can be simultaneously detected in a mixture (see Figure 1C). In order to analyse the SERRS efficiency and reproducibility of the Au@pNIPAM probes, the SERRS intensity at the most intense dye signal (1539 $\mathrm{cm}^{-1}$ for $\mathrm{AB}, 592 \mathrm{~cm}^{-1}$ for $\mathrm{NB}$ and $1616 \mathrm{~cm}^{-1}$ for MGI) was plotted as a function of particle concentration at $633 \mathrm{~nm}$ excitation laser wavelength (Figure S2). All plots showed linear correlation with small standard deviations over the range $(0.10-10.0) \mathrm{pM}$, being $0.10 \mathrm{pM}$ the lowest detectable nanoparticle concentration for all three dyes. Additionally, the stability of the SERRS signal intensity was monitored over a threemonth period and no significant decrease in intensity was observed (Figure S3). These results ruled out the possibility of dye degradation or leaching and confirmed the high stability and robustness of these SERS probes.

Au@pNIPAM SERRS tags were subsequently bioconjugated with antibodies against three different tumor biomarkers: EGFR, EpCAM and CD44. EGFR is a membrane tyrosine kinase receptor, expressed in different tumors of epithelial origin and has been validated as a target for cancer therapy.[54, 55] EpCAM is a type I membrane protein that is expressed in a variety of human epithelial tissues and cancer propagating cells.[56] CD44 is a cell surface glycoprotein, involved in cell-to-cell interactions, that has been implicated in several malignancies of epithelial origin and is recognized as a cancer stem cell marker. ${ }^{[57]}$ Bioconjugation was carried out via EDC/NHS chemistry, where the primary amine groups on the biomarkers reacted with EDC/NHS activated carboxyl groups on the microgels surface. 


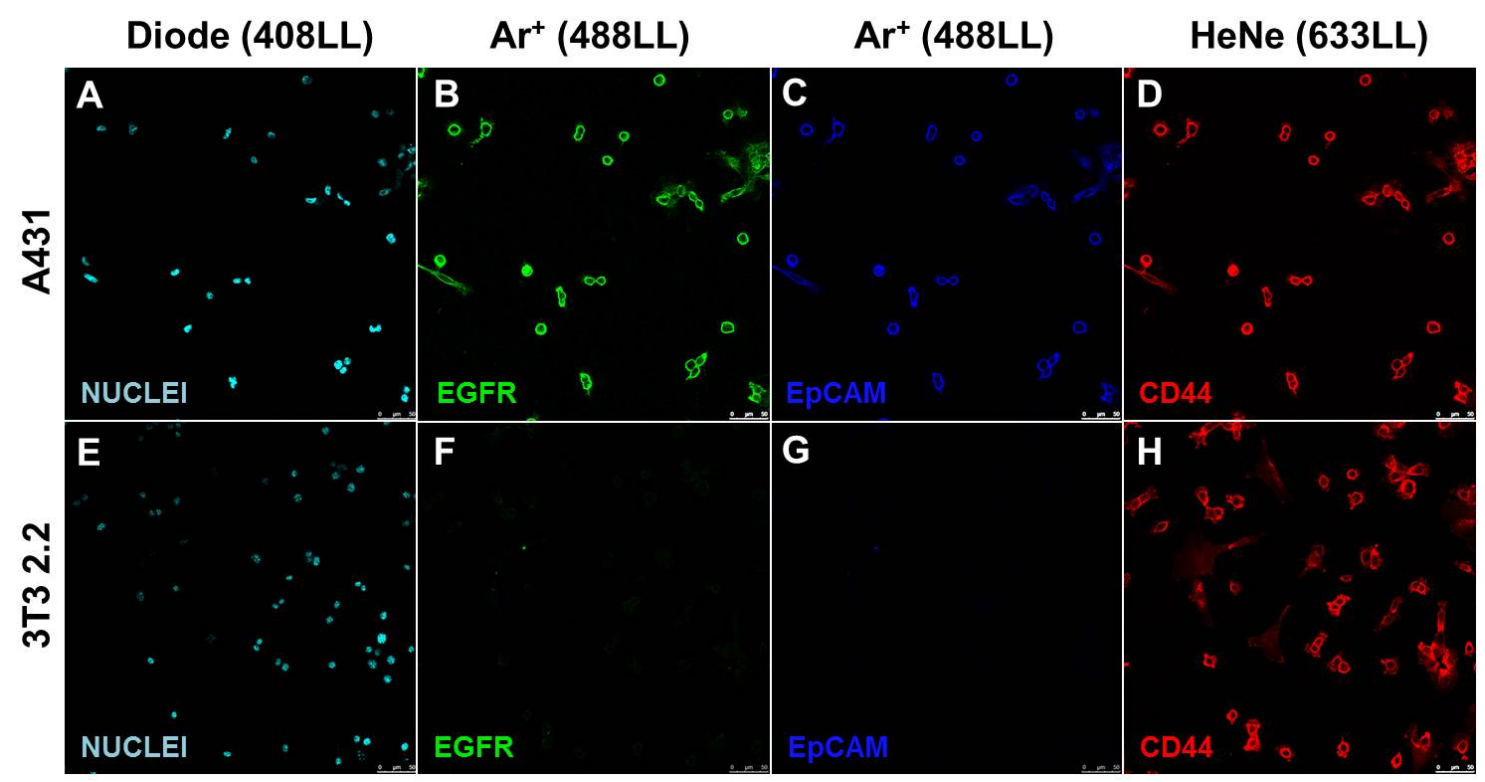

Figure 2. Fluorescence immunostaining of EGFR, EpCAM and CD44 expression in A431 and 3T3 2.2 cells. Confocal fluorescence microscopy images showing DAPI labelling of cell nuclei (A,E), EGFR staining with mouse anti-EGFR antibodies and goat anti-mouse antibodies conjugated to CF488 (B,F), EpCAM staining with rabbit anti-EpCAM antibodies and goat anti-rabbit antibodies conjugated to Alexa-fluor 594 $(\mathrm{C}, \mathrm{G})$, and CD44 staining with rat anti-CD44 antibodies and goat anti-rat antibodies conjugated to Alexa fluor $647(\mathrm{D}, \mathrm{H})$. DAPI and fluorophores were excited with the laser lines indicated over the images.

Targeted plasmonic detection and imaging of EGFR, EpCAM and CD44 were then assessed in mixed populations of human epithelial carcinoma A431 and nontumoral murine fibroblast $3 \mathrm{~T} 32.2$ cells cultured in vitro. Since these cell lines differed in the expression of the three selected biomarkers, this experiment was used to evaluate the targeting specificity of the SERRS-tags. Whereas the A431 cell line expressed EGFR,[58] EpCAM[59] and CD44,[60] the 3T3 2.2 cell line expressed CD44,[61] but neither EGFR[62] nor EpCAM.[63] To ascertain the differential expression of the biomarkers in A431 and 3T3 2.2 cell lines, immunofluorescence assays were also 
performed with the same specific antibodies used for Au@pNIPAM microgels bioconjugation. As shown in the confocal fluorescence microscopy images of Figure 2, the antibodies against EGFR and EpCAM specifically labeled the A431 (Figure 2B and 2C) but not the $3 \mathrm{~T} 32.2$ cells (Figure $2 \mathrm{~F}$ and $2 \mathrm{G}$ ), and the antibodies against CD44 detected both A431 and 3T3 2.2 cell lines (Figure 2D and 2H). Hence, the fluorescence immunophenotypic characterization indeed demonstrated that the A431 cells were EGFR+, EpCAM+ and CD44+, whereas the 3T3 2.2 cells were EGFR-, EpCAM- and CD44+. Importantly, this multiple label fluorescence assay, having three different emission colors, required the use of two laser excitation wavelengths, $488 \mathrm{~nm}\left(\mathrm{Ar}^{+}\right.$ laser) to detect CF488A and Alexa Fluor 594 conjugated to secondary antibodies used for detecting EGFR and EpCAM respectively, and a $633 \mathrm{~nm} H e N e$ laser for excitation of the Alexa Fluor 647 dye used for detecting anti-CD44.

The multiplexing capabilities of the SERRS-encoded tags were first evaluated toward targeting of cellular EGFR expression. To this end, a mixture of Au@NIPAM microgels conjugated to anti-EGFR antibodies and codified with $\mathrm{AB}$, NB or MGI, were added to a co-culture of A431 and 3T3 2.2 cells grown on glass coverslips. After washing unbound microgels, the cells were immunostained with mouse anti-EGFR and goat anti-mouse CF488 secondary antibodies, and with 4'-6-diamidine-2-phenyl indole (DAPI) as a control to reveal the presence of EGFR-expressing A431 tumor cells and cell nuclei, respectively by fluorescence microscopy. The merged bright field with fluorescence image of Figure 3A shows an A431 tumor cell expressing EGFR that is surrounded by three EGFR-negative 3T3 2.2 non-tumor cells. SERRS spectra (Figure 3) were recorded from areas corresponding to either the A431 cell or 3T3 2.2 cells (labeled with stars in Figure 3A). Whereas the characteristic SERRS peaks from MGI, NB and $\mathrm{AB}$ were identified in spectra recorded at the A431 cell surface (Figure 3F) no SERRS 
signals were detected at $3 \mathrm{~T} 32.2$ cells (Figure $3 \mathrm{G}$ ), indicating the absence of EGFR expression. Further confirmation of selective binding to the tumor cells for all three probes, spatial mappings of SERRS intensity at $420 \mathrm{~cm}^{-1}, 592 \mathrm{~cm}^{-1}$ and $748 \mathrm{~cm}^{-1}$ were obtained spanning the whole region shown in Figure 3A. SERRS mapping (Figure 3BE) demonstrated uniform and specific labeling of the EGFR-expressing A431 tumor cell (Figure 3A) with all three anti-EGFR pNIPAM SERRS tags. No significant Raman signals were detected from the 3T3 2.2 cells or in the surrounding glass surface. These results confirm that all three Raman codes successfully allowed the identification and imaging of EGFR in in vitro cultured cells by SERRS.
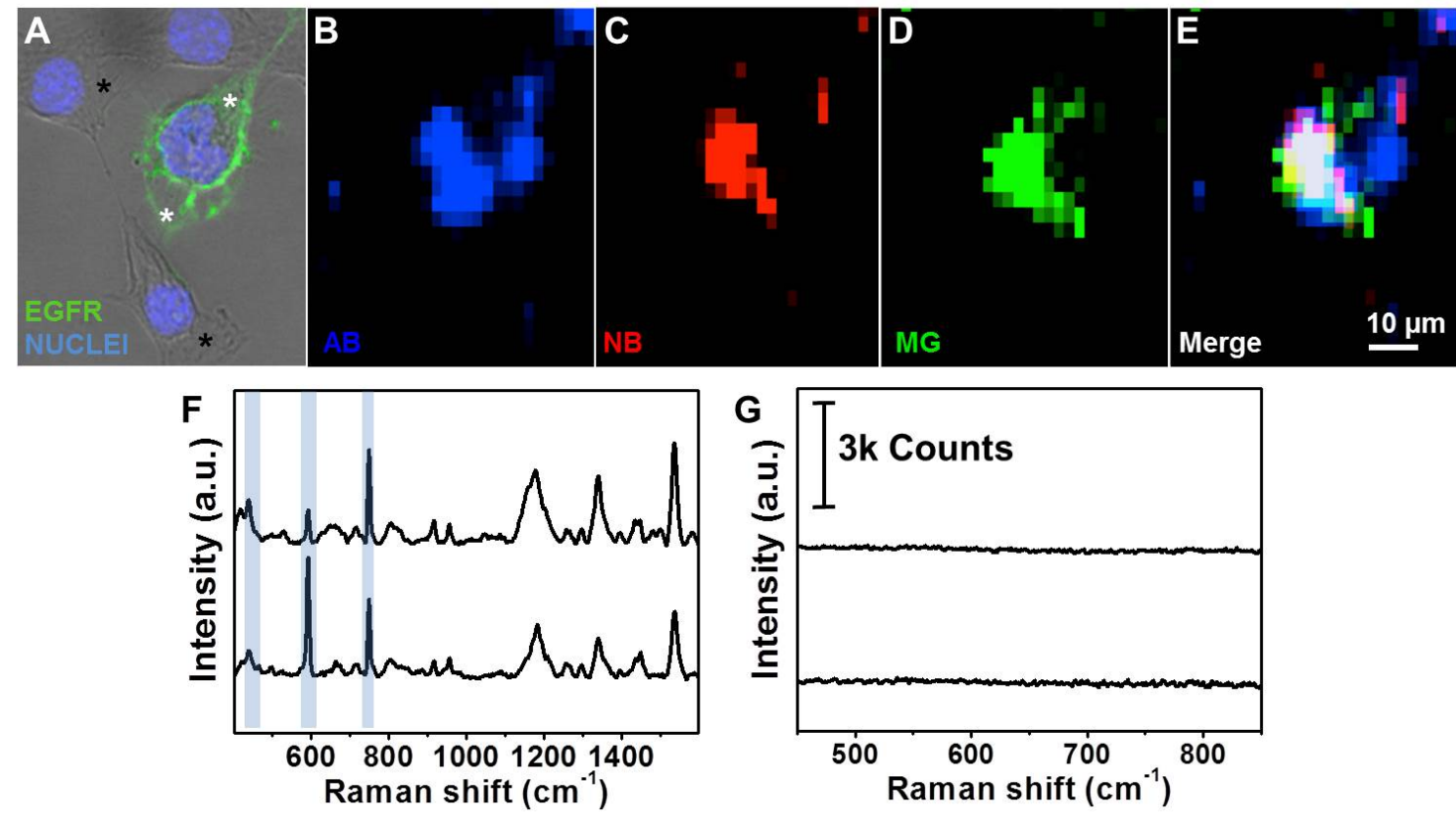

Figure 3. SERRS detection and imaging of EGFR expression. (A) Bright field and fluorescence confocal microscopy image showing A431 (EGFR positive) and 3T3 2.2 (EGFR negative) cells. (B-E) SERRS mappings recorded from the same area using the $748 \mathrm{~cm}^{-1}$ peak of $\mathrm{AB}(\mathrm{B}), 592 \mathrm{~cm}^{-1}$ peak of NB (C), $420 \mathrm{~cm}^{-1}$ peak of MGI (D). (E) is a merged image of the three mappings. $(F, G)$ SERRS spectra obtained at the areas indicated in panel A with white stars (F) and black stars (G). 
Finally, the multiplexing capability of our SERRS-encoded microgels was assessed for the simultaneous detection of three tumor-associated biomarkers (EGFR, EpCAM and CD44) in co-cultures of A431 and 3T3 2.2 cells (Scheme 2A). Au@pNIPAM microgels encoded with AB, NB or MGI were functionalized with specific antibodies against EGFR, EpCAM and CD44, respectively. The A431 and 3T3 2.2 cells grown as co-cultures on glass slides were incubated simultaneously with the different pNIPAM-SERRS tags. After washing to remove unbound particles, the cells were immunostained with anti-EGFR antibodies, their nuclei stained with DAPI and analyzed by Raman scattering and confocal microscopy.

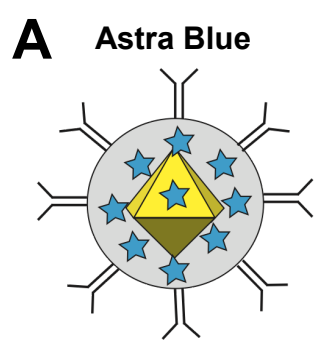

Mouse anti-EGFR

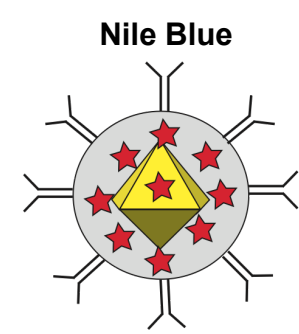

Rabbit Ab anti-EpCAM

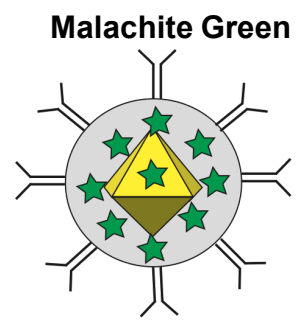

Rat anti-CD44

B
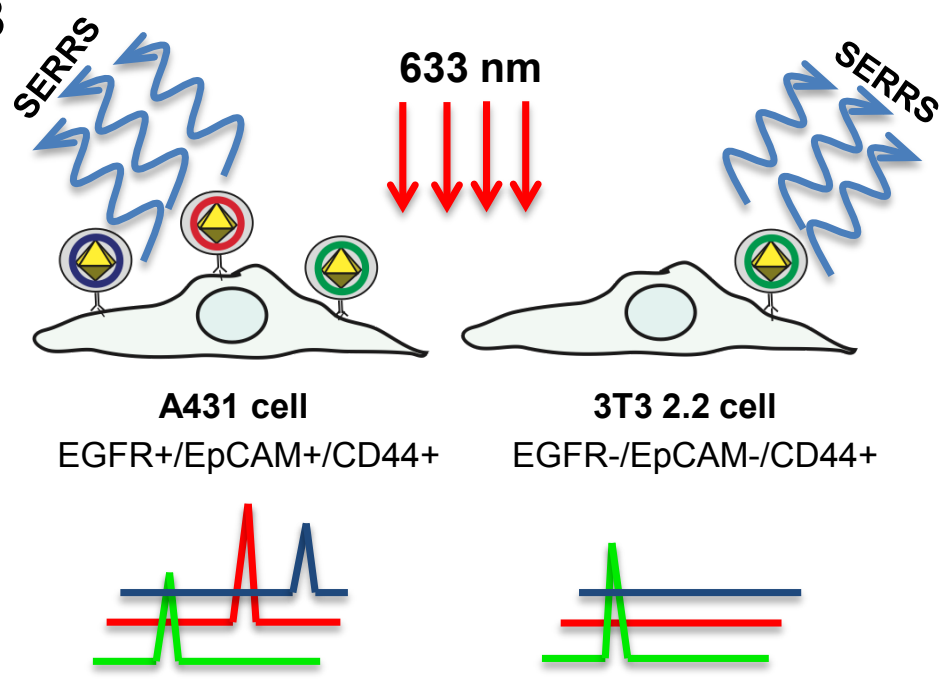

Raman Shift $\left(\mathrm{cm}^{-1}\right)$

Scheme 2. A) Au@pNIPAM SERRS tags indicating their Raman codification and targeting entities. B) Schematic representation of the SERRS immunophenotype detection of A431 and 3T3 2.2 cells. 
Since confocal microscopy analysis allowed us to differentiate both A431 and 3 T3 2.2 cells, an area containing both types of cells was selected to carry out the multiplexing SERRS analysis (Figure 4A). SERRS spectra were recorded at selected areas corresponding to A431 and 3T3 2.2 cells, indicated with stars in Figure 4A. As shown in Figure 4F, the SERRS spectra recorded on A431 cells displayed characteristic vibrational peaks of MGI, $\mathrm{NB}$ and $\mathrm{AB}$, thereby confirming the presence of all three types of pNIPAM SERRS tags and therefore the three tumor-associated biomarkers characteristic of A431 cells. On the contrary, SERRS spectra (Figure 4G) recorded in the areas indicated with white stars in Figure 4A only showed the characteristic MGI signals, meaning that these cells express CD44 only, i.e. they are 3T3 2.2 cells.

Addtionally, spatial mappings of SERRS at $420 \mathrm{~cm}^{-1}$ (MGI), $592 \mathrm{~cm}^{-1}$ (NB) and $748 \mathrm{~cm}^{-1}(\mathrm{AB})$ were recorded over the region shown in Figure 4A, so as to evaluate the surface distribution of tumor-associated biomarkers. Figure 4B, 4C and 4D shows SERRS maps for EGFR, EpCAM and CD44 expression, respectively. Anti-EGFR (AB) and anti-EpCAM (NB) SERRS-tags were specifically located on the cell expressing EGFR, A431, (Figure 4A), whereas anti-CD44 (MGI) SERRS-tags were present in both cell types (Figure 4D). Interestingly, the two 3T3 2.2 cells present at the center of the image seem to be weakly labeled with anti-CD44 SERRS tags, probably reflecting low CD44 expression. It is important to note that the levels of CD44 in the 3 T3 2.2 cell line were not homogeneous and even some 3T3 2.2 cells did not express it (see Figure 2H and S4). Reproducibility was assessed by recording SERRS maps from different areas and also from different experiments, which yielded similar results (Figure S5) Altogether, these results demonstrate that Au@pNIPAM SERRS tags allow targeted detection of EGFR, EpCAM or CD44 and selective imaging of A431 and 3T3 2.2 cell 
lines in vitro. Remarkably, whereas two different lasers ( $\mathrm{Ar}^{+} @ 488$ nm and HeNe@633 $\mathrm{nm}$ ) were necessary to detect the three cellular receptors by fluorescence, a single laser excitation line allowed reliable detection of three biomarkers by SERRS.
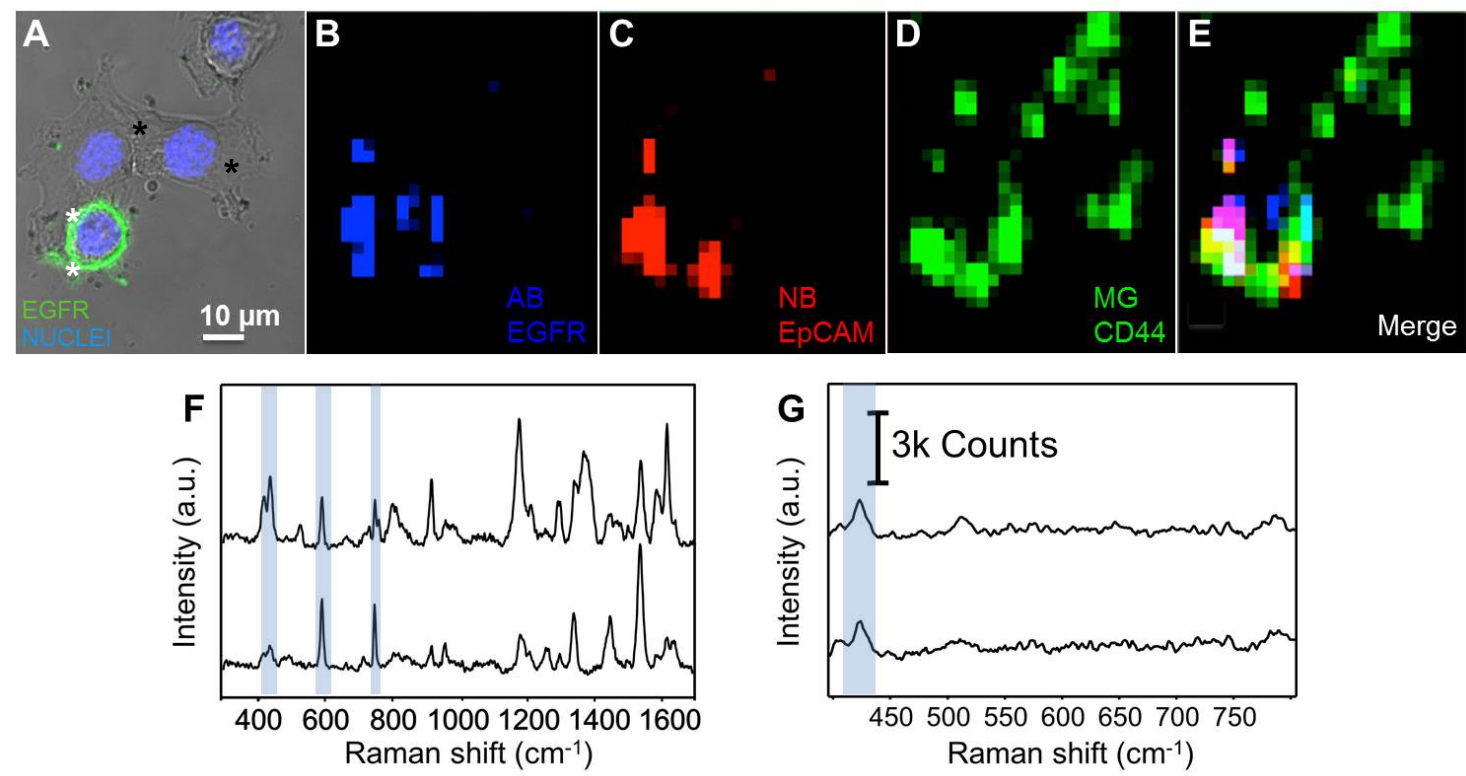

Figure 4. Multiplex detection and imaging of EGFR, EpCAM and CD44 by SERRS.

(A) Bright field and confocal fluorescence microscopy image showing A431 (EGFR positive) and 3t3 2.2 (EGFR negative) cells. (B-E) SERRS mappings recorded in the same area using the $748 \mathrm{~cm}^{-1}$ peak of AB (B), $592 \mathrm{~cm}^{-1}$ peak of NB (C), $420 \mathrm{~cm}^{-1}$ peak of MGI (D), and merged image (E) of the three mappings. (F,G) SERRS spectra obtained at the areas indicated in panel A with white (F) and black stars (G).

\section{Conclusions}

Stable, sensitive SERRS tags with multiplex capability were prepared by dye encoding of preformed pNIPAM-encapsulated Au octahedrons. This system overcomes particle aggregation issues that are often encountered during the fabrication of SERS probes. Importantly, the use of large Au octahedrons allowed us to achieve high resonance Raman scattering enhancements leading to reproducible high intensity 
signals, detectable even at $0.1 \mathrm{pM}$ particle concentration. Conjugation of SERRS encoded Au@pNIPAM microgels to antibodies for specific targeting to EGFR, EpCAM or CD44 allowed multiplex detection and imaging of these important tumor-associated biomarkers, for discrimination of A431 tumor and 3T3 2.2 non-tumor cells with a single excitation laser line. The SERRS labels presented in this work may be applied to highthroughput, multiplex assays involving encoded particles for in vitro screening and diagnostics such as flow-cytometry, enzyme-linked immunosorbent assay (ELISA) or automated microscopy.

\section{Experimental section}

Chemicals. $\mathrm{HAuCl}_{4} \cdot 3 \mathrm{H}_{2} \mathrm{O}$, benzyldimethylhexadecylammonium chloride (BDAC), butenoic acid, N-isopropylacrylamide (NIPAM, 97\%), Astra Blue (AB), Nile Blue (NB), poly(allylamine hydrochloride) (PAH, MW 56,000 g/mol), fetal bovine serum (FBS), trypsin-EDTA solution, formalin solution, phosphate buffer saline (PBS), goat serum, N-(3-dimethylaminopropyl)-N'-ethylcarbodiimide hydrochloride (EDC), Nhydroxysulfosuccinimide sodium salt, 2-(4-amidinophenyl)-1H -indole-6carboxamidine (DAPI) were purchased from Sigma-Aldrich. N,N'methylenebisacrylamide (BIS) and sodium azide were supplied by Fluka. 2,2'Azobis(2-methylpropionamidine) dihydrochloride (AAPH) was supplied by Acros Organics. Poly(acrylic acid) (PAA, MW 60,000 g/mol) was supplied by Polysciences INC. Malachite Green Isothiocyanate (MGI), Dulbecco's modified Eagle's medium (DMEM), penicillin streptomycin solution and Prolong anti-fade reagent were supplied by Life Technologies. All chemicals were used as received. Milli-Q grade water was used as solvent. 
Antibodies were rabbit anti-EpCAM (ab71916), rat anti-CD44 (ab119348), mouse antiEGFR (Sigma, E2156), goat anti-rat alexa-fluor 647 (Life technologies, A21247), goat anti-rabbit alexa-fluor 594 (Life technologies, A11072) and goat anti-mouse CF488 (Sigma, SAB4600388).

Gold Octahedrons. Au octahedrons were prepared by seeded growth using single

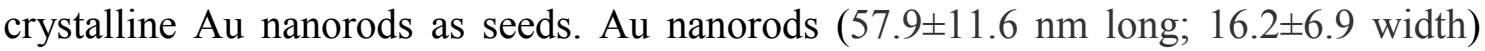
were synthesized as previously reported.[64] The growth solution was prepared by adding to $50 \mathrm{~mL}$ of BDAC $(10 \mathrm{mM}) 500 \mu \mathrm{L}$ of $\mathrm{HAuCl}_{4}(0.05 \mathrm{M})$ and $212 \mu \mathrm{L}$ of butenoic acid. The solution was kept at $60{ }^{\circ} \mathrm{C}$ until the yellow color disappeared (around 35 min) and then Au nanorods were added as seeds. The final concentration of $\mathrm{Au}$ nanorods was $0.016 \mathrm{mM}$. The mixture was allowed to react overnight at $60{ }^{\circ} \mathrm{C}$. Gold octahedrons were washed twice by centrifugation $(3,000 \mathrm{rpm}, 30 \mathrm{~min})$, the supernatant was discarded and the precipitate redispersed in $10 \mathrm{~mL}$ of water. The average size measured from TEM analysis was $87.1 \pm 4.3 \mathrm{~nm}$ side length.

Au@pNIPAM particles. $10 \mathrm{~mL}$ of as prepared Au colloids was heated at $70{ }^{\circ} \mathrm{C}$ under $\mathrm{N}_{2}$ flow and then NIPAM $(0.113 \mathrm{~g})$ and BIS $(0.0154 \mathrm{~g})$ were added under magnetic stirring. After $15 \mathrm{~min}$, the nitrogen flow was removed and the polymerization was initiated with the addition of $100 \mu \mathrm{L}$ of $0.1 \mathrm{M} \mathrm{AAPH}$ in water. After $2 \mathrm{~h}$ at $70{ }^{\circ} \mathrm{C}$, the white mixture was allowed to cool down to room temperature under stirring. Finally, it was diluted with water $(50 \mathrm{~mL})$, centrifuged (30 min at $1920 \mathrm{~g})$ and redispersed in water (fivefold). The average $\zeta$-potential of the particles is $+19.2 \pm 1.8 \mathrm{mV}$, most probably due to incorporation of ionic fragments from decomposition of the cationic initiator during 
NIPAM polymerization. The average diameter of the Au@pNIPAM particles is $402.9 \pm 2.3 \mathrm{~nm}$ at $25^{\circ} \mathrm{C}$.

EncodedAu@pNIPAM nanostructures. The encapsulation of Raman probes was carried out by simply adding dropwise the dye diluted in ethanol ( $\mathrm{AB}$ or $\mathrm{NB}$ ) or methanol (MGI) under gentle stirring to $10 \mathrm{~mL}$ of $0.9 \mathrm{mM} \mathrm{Au@pNIPAM} \mathrm{in} \mathrm{water.} \mathrm{The} \mathrm{final} \mathrm{dye}$ concentration was $10^{-4} \mathrm{M}$. The average $\zeta$-potential of the encoded particles was positive for all doped microgels $(+16.2 \pm 1.8 \mathrm{mV}$ and $+17.1 \pm 1.8 \mathrm{mV}$, respectively, for AB- and NB-doped microgels, but slightly less positive for MGI-doped microgels, $+7.6 \pm 1.5$ $\mathrm{mV}$ ). The mixture was gently stirred overnight and then added dropwise to $10 \mathrm{~mL}$ of PAA, for AB/NB-doped microgels, or PAH, for MGI-doped microgels, $(2 \mathrm{mg} / \mathrm{mL}, 6$ $\mathrm{mM} \mathrm{NaCl}$ ) aqueous solution (previously sonicated for $15 \mathrm{~min}$ ) under vigorous stirring. Stirring was continued overnight and then the mixture was centrifuged twice at $850 \mathrm{~g}$ for $40 \mathrm{~min}$ to remove excess polyelectrolyte and redispersed in $10 \mathrm{~mL}$ of water. After the washing step, the process was repeated in a similar way to deposit additional polyelectrolyte layers. Due to the charge provided by the dyes to the Au@pNIPAM microgels, the polyelectrolyte layers sequence on the microgels was PAA@PAH@PAA for AB- and NB-doped microgels and PAH@PAA for MGI-doped microgels. Three polyelectrolytes layers (PAA, PAH and PAA) were thus deposited on AB- and NBdoped microgels, whereas two layers (PAH and PAA) were deposited on MGI-doped microgels. The average diameter of the encoded Au@pNIPAM particles is 405.2 \pm 7.1 nm at $25^{\circ} \mathrm{C}$.

Cell lines and in vitro culture conditions. The human epidermoid carcinoma cell line A431 (ATCC, CRL-1555) and NIH 3T3 clone 2.2 murine fibroblasts (3T3 2.2) [62], 
were grown as a monolayer in DMEM, supplemented with 10\% FBS, $2 \mathrm{mM}$ glutamine, penicillin $(100 \mathrm{U} / \mathrm{mL})$ and streptomycin $(100 \mu \mathrm{g} / \mathrm{mL})$ at $37{ }^{\circ} \mathrm{C}$ in a humidified atmosphere containing $5 \% \mathrm{CO}_{2}$.

Immunofluorescence staining and confocal fluorescence microscopy analysis of EGFR, EpCAM and CD44 expression. A431 and 3T3 2.2 cell lines were separately seeded on sterile coverslips (13 mm diameter, VWR international) placed in 24-well plates at a density of 15,000 cells/well and grown for 18 hours. The cells were washed three times with $1 \mathrm{~mL}$ of PBS at room temperature, fixed with $0.5 \mathrm{~mL}$ of a formalin solution for 20 min at room temperature and washed three times with $1 \mathrm{~mL}$ of PBS. The coverslips were transferred to a wet chamber and blocked with $60 \mu \mathrm{L}$ of $10 \%(\mathrm{v} / \mathrm{v})$ goat serum solution in PBS for one hour. The coverslips were washed by immersion 5 times in PBS $(100 \mathrm{~mL})$, placed again in the wet chamber, and incubated with $60 \mu \mathrm{L}$ of $10 \%(\mathrm{v} / \mathrm{v})$ goat serum solution in PBS containing either rabbit anti-EpCAM, rat anti-CD44 or mouse anti-EGFR antibodies (1:100) for one hour at room temperature. Subsequently, the coverslips were washed by immersion 10 times in PBS, and the excess of liquid was removed by touching a kimwipe with the edge of the coverslip. Next the coverslips were incubated for 30 minutes at room temperature with $60 \mu \mathrm{L}$ of a $10 \%(\mathrm{v} / \mathrm{v})$ goat serum solution in PBS containing the respective goat anti-rat Alexa-fluor 647, goat antirabbit Alexa-fluor 594 or goat anti-mouse CF488 secondary antibodies (1:500) and $1 \mu \mathrm{L}$ of a DAPI solution in sterile milli-Q water (1:500). The samples were washed in PBS as indicated above, mounted with $2 \mu \mathrm{L}$ of Prolong on glass slides and analyzed by confocal fluorescence microscopy (Leica TCS SP5 multispectral confocal system) employing a Diode (405 nm), an Argon (488 nm) or a HeNe (633nm) laser when indicated. 
Conjugation of SERRS particles with antibodies. The SERRS-encoded Au@pNIPAM microgels $(100 \mu \mathrm{L}$ at $0.2 \mathrm{mM}$ in gold metal) were activated for two hours in $100 \mathrm{mM}$ MES buffer ( $\mathrm{pH} 5.5$ ) containing $20 \mathrm{mM}$ EDC and $40 \mathrm{mM}$ NHS, which were prepared immediately before conjugation in $10 \mathrm{mM}$ MES buffer (pH 5.5). Next, the microgels were washed by centrifugation ( $1520 \mathrm{~g}$ for $20 \mathrm{~min}$ ) with $500 \mu \mathrm{L}$ of sterile milli-Q water and resuspended in $100 \mu \mathrm{L}$ of sterile PBS containing $10 \mu \mathrm{g}$ of the corresponding antibodies as indicated. The antibody conjugation reaction was performed at room temperature for 2 hours followed by overnight incubation at $4{ }^{\circ} \mathrm{C}$. Next, the samples were washed twice by centrifugation with $500 \mu \mathrm{L}$ of sterile PBS and the microgels were resuspended in $100 \mu \mathrm{L}$ of sterile PBS containing $10 \%(\mathrm{v} / \mathrm{v})$ goat serum and $0.02 \%(\mathrm{v} / \mathrm{v})$ sodium azide. The SERRS tags were stored at $4{ }^{\circ} \mathrm{C}$ for no more than a week prior to use.

Adhesion of SERRS-tags to in vitro cultured cells, Raman and confocal fluorescence microscopy analyses. Mixtures of A431 and 3T3 2.2 cell lines were seeded on sterile coverslips (13 mm diameter, VWR international) placed in 24-well plates at a density of 5,000 cells/well with a percentage of $30 \%$ A431 cells and 70\% 3T3 2.2 cells and grown for 18 hours. Before seeding the cells, two perpendicular lines were marked in the center of the coverslip with a glasscutter to allow the localization of a given group of cells under both microscopes. The cells were washed three times with $1 \mathrm{~mL}$ of PBS at room temperature, fixed with $0.5 \mathrm{~mL}$ of formalin for $20 \mathrm{~min}$ and washed three times with $1 \mathrm{~mL}$ of PBS. The coverslips were transferred to a wet chamber and the cells were first blocked with $60 \mu \mathrm{L}$ of $10 \%$ (v/v) goat serum solution in PBS for one hour and then washed by immersion 5 times in PBS $(100 \mathrm{~mL})$. The coverslips were placed again in the 
wet chamber and incubated for two hours at room temperature with the antibodyconjugated SERRS-tags as indicated $(20 \mu \mathrm{L}$ of each microgel solution). Next, the coverslips were washed by immersion 10 times in PBS and the excess of liquid was removed with a kimwipe as explained above. The cells were stained for EGFR by incubating the coverslips with $60 \mu \mathrm{L}$ of a $10 \%(\mathrm{v} / \mathrm{v})$ goat serum solution in PBS containing mouse anti-EGFR antibodies (1:100) for $30 \mathrm{~min}$ at room temperature. The coverslips were rinsed by immersion 5 times in PBS and incubated for 10 min with 60 $\mu \mathrm{L}$ of $10 \%(\mathrm{v} / \mathrm{v})$ goat serum solution in PBS containing goat anti-mouse CF488 antibodies (1:500) and $1 \mu \mathrm{L}$ of a DAPI solution in sterile milli-Q water (1:500). Next, the coverslips were washed 5 times in PBS and mounted with $2 \mu \mathrm{L}$ of Prolong on glass slides. The cells located at the intersection of the lines marked on the glass coverslips were analyzed under a confocal Raman microscope and subsequently by confocal fluorescence microscopy (Leica TCS SP5 multispectral confocal system) employing a diode laser $(405 \mathrm{~nm})$ and an $\mathrm{Ar}^{+}(488 \mathrm{~nm})$ laser.

Characterization. Optical characterization was carried out by UV-vis-NIR spectroscopy with an Agilent 8453 spectrophotometer. A JEOL JEM 1010 transmission electron microscope (TEM) operating at an acceleration voltage of $100 \mathrm{kV}$ was used for particle size analysis and low magnification imaging.

SERRS experiments were conducted with a Renishaw InVia Reflex system. The spectrograph used a high-resolution grating $\left(1,800\right.$ grooves $\left.\mathrm{mm}^{-1}\right)$ with additional bandpass filter optics, a confocal microscope, and a 2D-CCD camera. Excitation was carried out at $633 \mathrm{~nm}(\mathrm{HeNe})$ and laser power at the sample of $9.46 \mathrm{~mW}$. SERRS characterization of doped nanoparticles was done using a macrosampler accessory to measure in liquid state. SERRS images were obtained using a SERS point-mapping 
method with a 20x objective (N.A. 0.40), which provided a spatial resolution of about $2.6 \mu \mathrm{m}^{2}$. It created a spectral image by measuring the SERRS spectrum of each pixel of the image, one at a time. A computer-controlled $x-y$ translation stage was scanned in 2.6 $\mu \mathrm{m}$ (x-axis) and $2.6 \mu \mathrm{m}$ (y-axis) steps. The SERRS images of each well were decoded using the characteristic peak intensities of the three Raman reporter molecules using WiRE software V 3.4 (Renishaw, U.K,). SERRS spectra were analyzed using Grams software (Thermo Scientific, USA).

\section{Supporting Information}

Supporting Information is available from the Wiley Online Library or from the author.

\section{Acknowledgements}

This work was supported by the European Research Council (PLASMAQUO, 267867) and by the Spanish MINECO (MAT2013-45168-R and MAT2013-46101-R), by the Xunta de Galicia/FEDER (Grant GPC2013-006; INBIOMED-FEDER “Unha maneira de facer Europa")

Received: ((will be filled in by the editorial staff))

Revised: ((will be filled in by the editorial staff)) Published online: ((will be filled in by the editorial staff))

\section{References}

[1] W. A. Woodward, E. P. Sulman, Cancer Metast. Rev. 2008, 27, 459.

[2] J. A. Ludwig, J. N. Weinstein, Nat. Rev. Cancer 2005, 5, 845.

[3] R. Leth-Larsen, R. R. Lund, H. J. Ditzel, Mol. Cell. Proteomics 2010, 9, 1369.

[4] P. Lang, K. Yeow, A. Nichols, A. Scheer, Nat. Rev. Drug Discov. 2006, 5, 343.

[5] S. F. Kingsmore, Nat. Rev. Drug Discov. 2006, 5, 310.

[6] Y. Feng, T. J. Mitchison, A. Bender, D. W. Young, J. A. Tallarico, Nat. Rev. Drug Discov. 2009, 8, 567.

[7] K. Braeckmans, S. C. De Smedt, M. Leblans, R. Pauwels, J. Demeester, Nat. Rev. Drug Discov. 2002, 1, 447. 
[8] S. Birtwell, H. Morgan, Integr. Biol. 2009, 1, 345.

[9] R. Wilson, A. R. Cossins, D. G. Spiller, Angew. Chem., Int. Ed. 2006, 45, 6104.

[10] B. H. Jun, H. Kang, Y. S. Lee, D. H. Jeong, Molecules 2012, 17, 2474.

[11] K. D. Bake, D. R. Walt, Annu. Rev. Anal. Chem. 2008, 1, 515.

[12] M. E. Dickinson, G. Bearman, S. Tille, R. Lansford, S. E. Fraser, BioTechniques 2001, 31, 1272.

[13] H. T. Maecker, J. P. McCoy, R. Nussenblatt, Nat. Rev. Immunol. 2012, 12, 191.

[14] Y. Q. Wang, B. Yan, L. X. Chen, Chem. Rev. 2013, 113, 1391.

[15] L. Wang, M. B. O'Donoghue, W. H. Tan, Nanomedicine 2006, 1, 413.

[16] J. P. Nolan, D. S. Sebba, Recent Advances in Cytometry, Part A: Instrumentation, Methods, Fifth Edition 2011, 102, 515.

[17] T. Haselgrubler, M. Haider, B. Z. Ji, K. Juhasz, A. Sonnleitner, Z. Balogi, J. Hesse, Anal. Bioanal. Chem. 2014, 406, 3279.

[18] T. M. Cotton, S. G. Schultz, R. P. Vanduyne, J. Am. Chem. Soc. 1982, 104, 6528.

[19] S. Abalde-Cela, P. Aldeanueva-Potel, C. Mateo-Mateo, L. Rodriguez-Lorenzo, R. A. Alvarez-Puebla, L. M. Liz-Marzan, J. R. Soc. Interface 2010, 7, S435.

[20] Z. A. Nima, A. Biswas, I. S. Bayer, F. D. Hardcastle, D. Perry, A. Ghosh, E. Dervishi, A. S. Biris, Drug Metab. Rev. 2014, 46, 155.

[21] P. D. Howes, R. Chandrawati, M. M. Stevens, Science 2014, 346, 53.

[22] M. Vendrell, K. K. Maiti, K. Dhaliwal, Y. T. Chang, Trends Biotechnol. 2013, $31,249$.

[23] C. L. Zavaleta, E. Garai, J. T. C. Liu, S. Sensarn, M. J. Mandella, D. Van de Sompel, S. Friedland, J. Van Dam, C. H. Contag, S. S. Gambhir, Proc. Natl. Acad. Sci. U. S. A. 2013, 110, 10062. 
[24] G. McNay, D. Eustace, W. E. Smith, K. Faulds, D. Graham, Appl. Spectrosc. 2011, 65, 825 .

[25] Y. L. Wang, S. Schlucker, Analyst 2013, 138, 2224.

[26] X. M. Qian, X. H. Peng, D. O. Ansari, Q. Yin-Goen, G. Z. Chen, D. M. Shin, L. Yang, A. N. Young, M. D. Wang, S. M. Nie, Nat. Biotechnol. 2008, 26, 83.

[27] C. M. MacLaughlin, N. Mullaithilaga, G. S. Yang, S. Y. Ip, C. Wang, G. C. Walker, Langmuir 2013, 29, 1908.

[28] S. P. Mulvaney, M. D. Musick, C. D. Keating, M. J. Natan, Langmuir 2003, 19, 4784.

[29] C. Fernandez-Lopez, C. Mateo-Mateo, R. A. Alvarez-Puebla, J. Perez-Juste, I. Pastoriza-Santos, L. M. Liz-Marzan, Langmuir 2009, 25, 13894.

[30] L. Rodriguez-Lorenzo, Z. Krpetic, S. Barbosa, R. A. Alvarez-Puebla, L. M. LizMarzan, I. A. Prior, M. Brust, Integr. Biol. 2011, 3, 922.

[31] A. Samanta, K. K. Maiti, K. S. Soh, X. J. Liao, M. Vendrell, U. S. Dinish, S. W. Yun, R. Bhuvaneswari, H. Kim, S. Rautela, J. H. Chung, M. Olivo, Y. T. Chang, Angew. Chem., Int. Ed. 2011, 50, 6089.

[32] M. X. Yang, T. Chen, W. S. Lau, Y. Wang, Q. H. Tang, Y. H. Yang, H. Y. Chen, Small 2011, 7, 2412.

[33] S. Ip, C. M. MacLaughlin, N. Gunari, G. C. Walker, Langmuir 2011, 27, 7024.

[34] Z. A. Nima, M. Mahmood, Y. Xu, T. Mustafa, F. Watanabe, D. A. Nedosekin, M. A. Juratli, T. Fahmi, E. I. Galanzha, J. P. Nolan, A. G. Basnakian, V. P. Zharov, A. S. Biris, Sci. Rep. 2014, 4, 4752.

[35] U. S. Dinish, G. Balasundaram, Y. T. Chang, M. Olivo, Sci. Rep. 2014, 4, 4075.

[36] S. Lee, H. Chon, J. Lee, J. Ko, B. H. Chung, D. W. Lim, J. Choo, Biosens. Bioelectron. 2014, 51, 238. 
[37] A. Pallaoro, G. B. Braun, M. Moskovits, Proc. Natl. Acad. Sci. U. S. A. 2011, 108, 16559.

[38] H. Yuan, Y. Liu, A. M. Fales, Y. L. Li, J. Liu, T. Vo-Dinh, Anal. Chem. 2013, $85,208$.

[39] P. C. Naha, K. Bhattacharya, T. Tenuta, K. A. Dawson, I. Lynch, A. Gracia, F. M. Lyng, H. J. Byrne, Toxicol. Lett. 2010, 198, 134.

[40] M. A. Cooperstein, H. E. Canavan, Biointerphases 2013, 8.

[41] T. L. Sun, G. Y. Qing, Adv. Mater. 2011, 23, H57.

[42] M. A. Cooperstein, H. E. Canavan, Langmuir 2010, 26, 7695.

[43] B. R. Saunders, N. Laajam, E. Daly, S. Teow, X. H. Hu, R. Stepto, Adv. Colloid Interface Sci. 2009, 147-48, 251.

[44] Y. Guan, Y. J. Zhang, Soft Matter 2011, 7, 6375.

[45] M. R. Islam, A. Ahiabu, X. Li, M. J. Serpe, Sensors 2014, 14, 8984.

[46] J. H. Kim, T. R. Lee, Chem. Mater. 2004, 16, 3647.

[47] J. Perez-Juste, I. Pastoriza-Santos, L. M. Liz-Marzan, J. Mater. Chem. A 2013, $1,20$.

[48] R. A. Alvarez-Puebla, R. Contreras-Caceres, I. Pastoriza-Santos, J. Perez-Juste, L. M. Liz-Marzan, Angew. Chem., Int. Ed. 2009, 48, 138.

[49] R. Contreras-Caceres, S. Abade-Cela, P. Guardia-Giros, A. Fernandez-Barbero, J. Perez-Juste, R. A. Alvarez-Puebla, L. M. Liz-Marzan, Langmuir 2011, 27, 4520.

[50] R. Contreras-Caceres, I. Pastoriza-Santos, R. A. Alvarez-Puebla, J. Perez-Juste, A. Fernandez-Barbero, L. M. Liz-Marzan, Chem.-Eur. J. 2010, 16, 9462.

[51] Y. Lu, Y. Mei, M. Drechsler, M. Ballauff, Angew. Chem., Int. Ed. 2006, 45, 813.

[52] S. Carregal-Romero, N. J. Buurma, J. Perez-Juste, L. M. Liz-Marzan, P. Herves, Chem. Mater. 2010, 22, 3051. 
[53] T. Kawano, Y. Niidome, T. Mori, Y. Katayama, T. Niidome, Bioconjugate Chem. 2009, 20, 209.

[54] N. E. Hynes, H. A. Lane, Nat. Rev. Cancer 2005, 5, 341.

[55] N. Normanno, S. Tejpar, F. Morgillo, A. De Luca, E. Van Cutsem, F. Ciardiello, Nat. Rev. Clin. Oncol. 2009, 6, 519.

[56] M. Munz, P. A. Baeuerle, O. Gires, Cancer Res. 2009, 69, 5627.

[57] M. Zoller, Nat. Rev. Cancer 2011, 11, 254.

[58] Z. Novy, P. Barta, J. Mandikova, M. Laznicek, F. Trejtnar, Nucl. Med. Biol. 2012, 39, 893.

[59] J. Jain, G. Veggiani, M. Howarth, Cancer Res. 2013, 73, 2310.

[60] G. Stapleton, A. Malliri, B. W. Ozanne, J. Cell Sci. 2002, 115, 2713.

[61] C. Treese, A. Mittag, E. Lange, A. Tarnok, A. Loesche, F. Ernmrich, J. Lehmann, U. Sack, Cytometry A 2008, 73A, 351.

[62] A. M. Honegger, T. J. Dull, S. Felder, E. Vanobberghen, F. Bellot, D. Szapary, A. Schmidt, A. Ullrich, J. Schlessinger, Cell 1987, 51, 199.

[63] K. Sterzynska, B. Kempisty, P. Zawierucha, M. Zabel, Fol. Histochem. Cyto. 2012, 50, 534 .

[64] B. Nikoobakht, M. A. El-Sayed, Chem. Mater. 2003, 15, 1957. 